\title{
EDITORIAL
}

\section{Past in review and future plans}

\author{
Yi QIAN \\ Department of Environmental Science and Engineering, Tsinghua University, Beijing 100084, China
}

(C) Higher Education Press and Springer-Verlag 2009

Welcome to 2009 and Volume 3 of Frontiers of Environmental Science \& Engineering in China. Since its inception just two years ago, the journal has grown and evolved considerably. It has built a substantial readership and is proving a useful vehicle for authors to publish rigorously reviewed research achievements in the discipline of environmental science and engineering in China.

Submissions to Frontiers of Environmental Science \& Engineering in China are growing. In the past two years we published 152 papers from 78 Chinese universities and institutions. With the number of original submissions increasing from every issue to the next, the journal has gained a firm foot as the place to publish original research 'frontiers' in the field of environmental science and engineering in China. Since Issue 4, 2008, the journal has been devoted completely to publish original English research papers.

With a focus on environmental challenges facing China, one of the fastest developing economies in the world, we have published Hot Topics columns since the first issue. The topics have covered diversified fields such as Water Pollution Control, Air Pollution Control, Environmental Management, Lake Eutrophication, and so on. Each Hot Topic column is led by a Feature Article contributed by famous scientists from not only China but all over the world, followed by a collection of relevant research papers.

We are planning to make Frontiers of Environmental Science \& Engineering in China fully international in scope and high standard in quality. We will invite more scientists and scholars from outside of China to work with us in the editorial board, expand the referee group, and attract more international submissions and readers.

We hope that you have enjoyed Frontiers of Environmental Science \& Engineering in China so far. We thank all the authors and referees who have contributed to the development of the journal and we appreciate the continuing attention and support from our colleagues in the environmental science and engineering community. We hope more and more international friends will join us in Frontiers of Environmental Science \& Engineering in China to advance the discipline of environmental science and engineering.

All the best for 2009 .

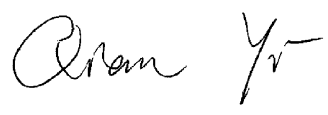

Editor-in-Chief

Received November 28, 2008

E-mail: qiany@tsinghua.edu.cn 